\title{
Higher Incidence Pathologies in Installations of Solar Energy, Gas, Cooling, Heating and Ventilation
}

\author{
Manuel J. Carretero-Ayuso \\ Musaat Foundation and University of Extremadura, Spain; carreteroayuso@yahoo.es
}

\begin{abstract}
This paper focuses on the study and quantifications of pathologies in solar energy, gas, cooling, heating and ventilation installations, based on complaints filed in the courts by the owners of a large number of houses in which errors appeared in those installations. The relevant complaints filed across all of Spain were studied, in what is an important contribution to forensic engineering, given that access to the outcome of civil court cases is seldom obtained. The representativeness of the data is not partial but total, since the entirety of cases existing in the period under study was part of the sample, enabling us to consider this to be a general exposition on the epidemiology of construction pathologies in installations in houses in Spain. It should be noted that the Spanish construction sector is one of the most problematic ones, due to the dissatisfaction generated in homeowners, and as it is one of the ones leading to the highest number of complaints filed with consumer protection bureaus and in the courts. In the investigation, results have been obtained for each of the installations (183 cases in total), according to the type of anomaly (the most important are dysfunctions, leaks and humidity), the pathological origin (poorly arranged encounters, omissions of elements, among others) and the type of construction where it is produced (especially in block dwellings).
\end{abstract}

Keywords: Installations, Complaints, Construction Pathologies.

\section{Introduction}

The purpose of an HVAC installation is to provide correct heating, ventilation and cooling, reliably maintaining comfortable values of humidity, temperature, and air quality, despite changes that might occur externally (Cohen et al. 2017). Accordingly, these installations (heating, ventilation and cooling) are key in air treatment, dehumidification, etc. Solar energy and gas supply installations further meet these needs, providing greater comfort. Indeed, in some context the set of these five types of installations are referred to as comfortability installations.

Recently, Yang et al. (2018) planned a fault detection mechanism for these installations, developing a method based of prognoses using synthetic data of temporal series through simulations in computer programmes. A year earlier, Turner et al. (2017) published a procedure for fault detection in buildings with some of these installations.

The scientific literature especially covers heating, ventilation, and cooling installations, from different perspectives. In 2018, a study was published identifying various factors affecting risk to cost and time in construction (Mosaad et al. 2018). In another perspective, Ruano et al. (2018) showed that half the energy consumption in residential and non-residential buildings was basically used by heating and cooling. It is for this reason that other authors (Wu and Sun 2011) consider it useful to develop methods of verification of certain parameters, through the use of energy flow models; including the study of air flow and the cooling/heating load (Cetin and Kallus 2016). 
For Behfar et al. (2017), the detection and diagnosis of faults in buildings' installation systems (especially when those faults convert into pathology problems) is of interest given that they allow the reduction of consumptions and operating costs, thus being a useful work tool for all technicians (engineers as well as architects).

One of the main limitations for the ample and in-depth knowledge of problems in installations is that a part of the reviewed literature has relied on observation processes or on surveys more or less focused on buildings of a specific developer or builder. Moreover, the lower number of problems existing therein in relation to other units more prone to pathologies (such as roofs, facades and structures) lead to them being less known.

The purpose of this research is to identify the most important types of anomalies in these types of installations, as well as their recurrence, based on judicial complaints made across all of Spain by building owners. The knowledge of these anomalies will be useful to designers, construction managers, and maintenance supervisors.

\section{Methodology}

This research analysed the data corresponding to the policies dated 2014-2016 of the civil responsibility insurance of Spanish technical architects and building engineers (Musaat 20142016 ) that saw complaints by owners related to construction problems (Serjuteca 2014-2016). This data was sourced from the Musaat Foundation's study "National statistical analysis on construction anomalies" (Carretero-Ayuso and Moreno-Cansado 2016), that aimed to identify the most frequent anomalies in the Spanish construction secto When a building builder do not solve complaints against the technicians that participt and construction managers. This is done main by civil responsibility insurance, which, in turn, is not required in Spain for developer and

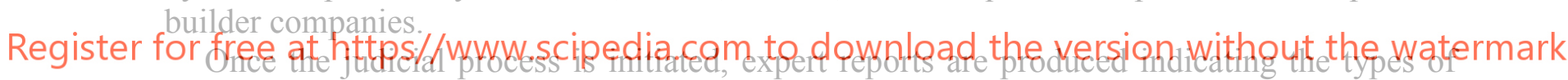

anomalies and in which construction elements or installations the problems occur. It is from this database, owned by the insurer of the technical architects and building engineers in question, that this study obtains all its resources and values. In this regard, it should be mentioned that, as a requirement to include the data in this research, it was determined that data points would only be considered when the respective court sentence was final and unappealable in any higher courts, often years after the complaint was first filed.

All the complaints filed in the country were analysed and protocolised, with 183 cases being found (number of times an anomaly was counted) related to the installations being study: 'Solar Energy' (I1), 'Gas' (I2), 'Cooling' (I3), 'Heating' (I4) and 'Ventilation' (I5).

The classes were classified into 4 groups, each representing a different type of anomaly that was the object of a complaint by owners, according to the conclusions of the relevant technical reports. The types of anomalies are: 'Fissures in the cladding' (A1), 'Deficient ventilation (A2), 'Leaks or humidities' (A3) and 'Dysfunctions' (A4).

The pathological origins leading to these anomalies were identified and catalogued into 4 types: 'Inadequate tail-ends' (OP1), 'Omission of elements' (OP2), 'Irregularities and deficiencies' (OP3), and 'Various' (OP4). 
The types of construction studied were: 'Detached houses' (V1), 'Attached houses' (V2) and 'Block dwellings' (V3).

\section{Results}

\subsection{General Values by Installation}

The values obtained in the five installations were very different from one another. As shown in Figure 1, ventilation $(15=42 \%)$ accounts for the greatest percentage, followed by heating $(\mathrm{I} 4=32 \%)$. In last place are solar energy installations $(\mathrm{I} 1=2 \%)$.
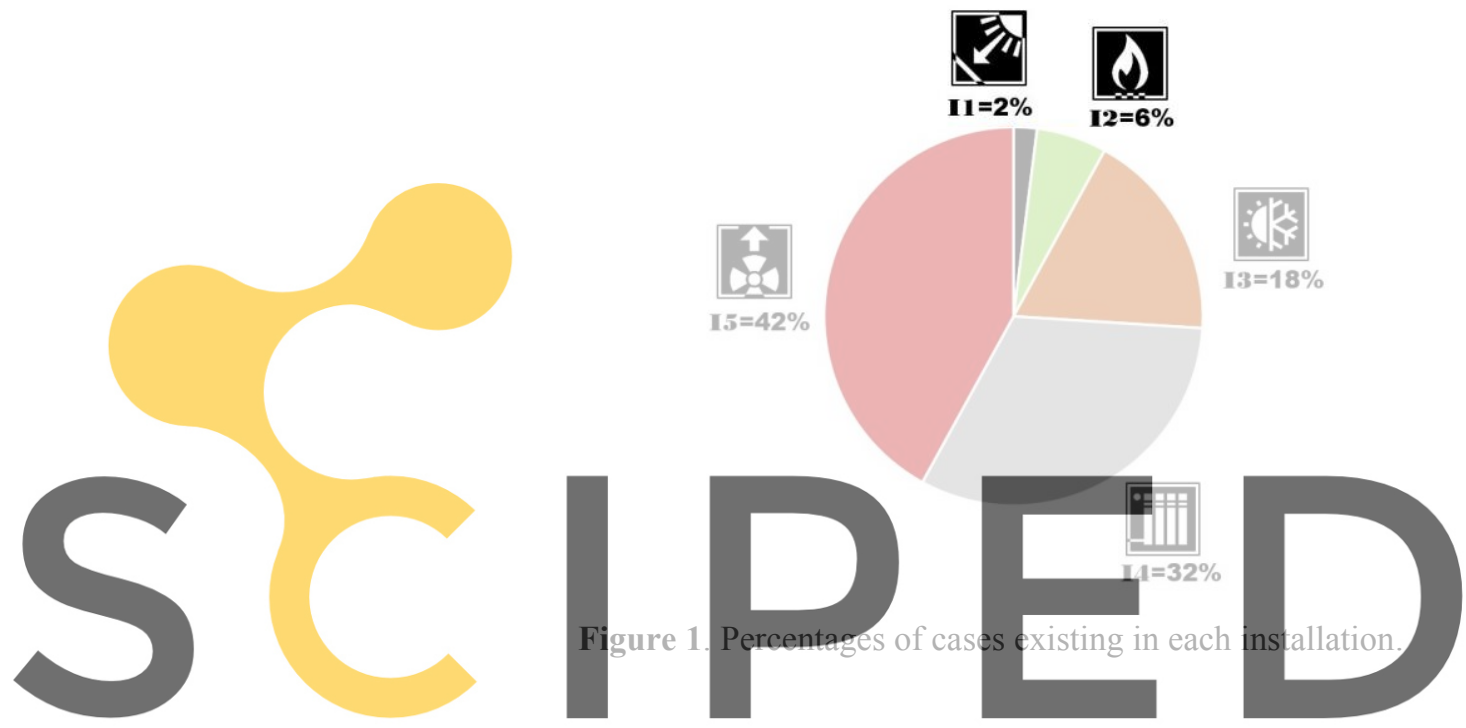

3.2 Values by Type of Anomaly

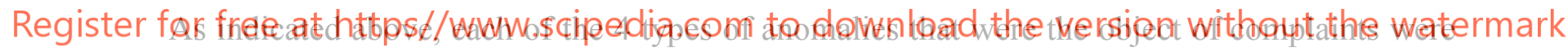

analysed. The one with the greatest prevalence was 'Dysfunctions' (A4=64\%), a term that has grouped within it a series of anomalous and poorly functioning processes. As shown in Figure 2, 'Leaks or humidities' (A3=19\%) are placed second.

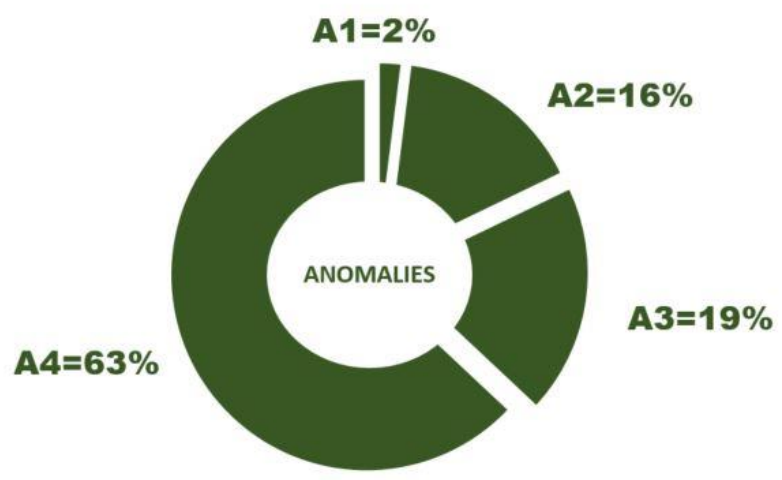

Figure 2. General percentages of the types of anomalies found in the research. 
In order to further deepen and break down the information on the prevalence of the anomalies for each installation, Figure 3 was produced, showing the weight of each of them. It can be seen that heating and cooling have three types of anomalies each, while ventilation and gas installations have two types. Finally, we can observe that thermal solar energy installations concentrate all their anomalies in a single type ('dysfunctions').
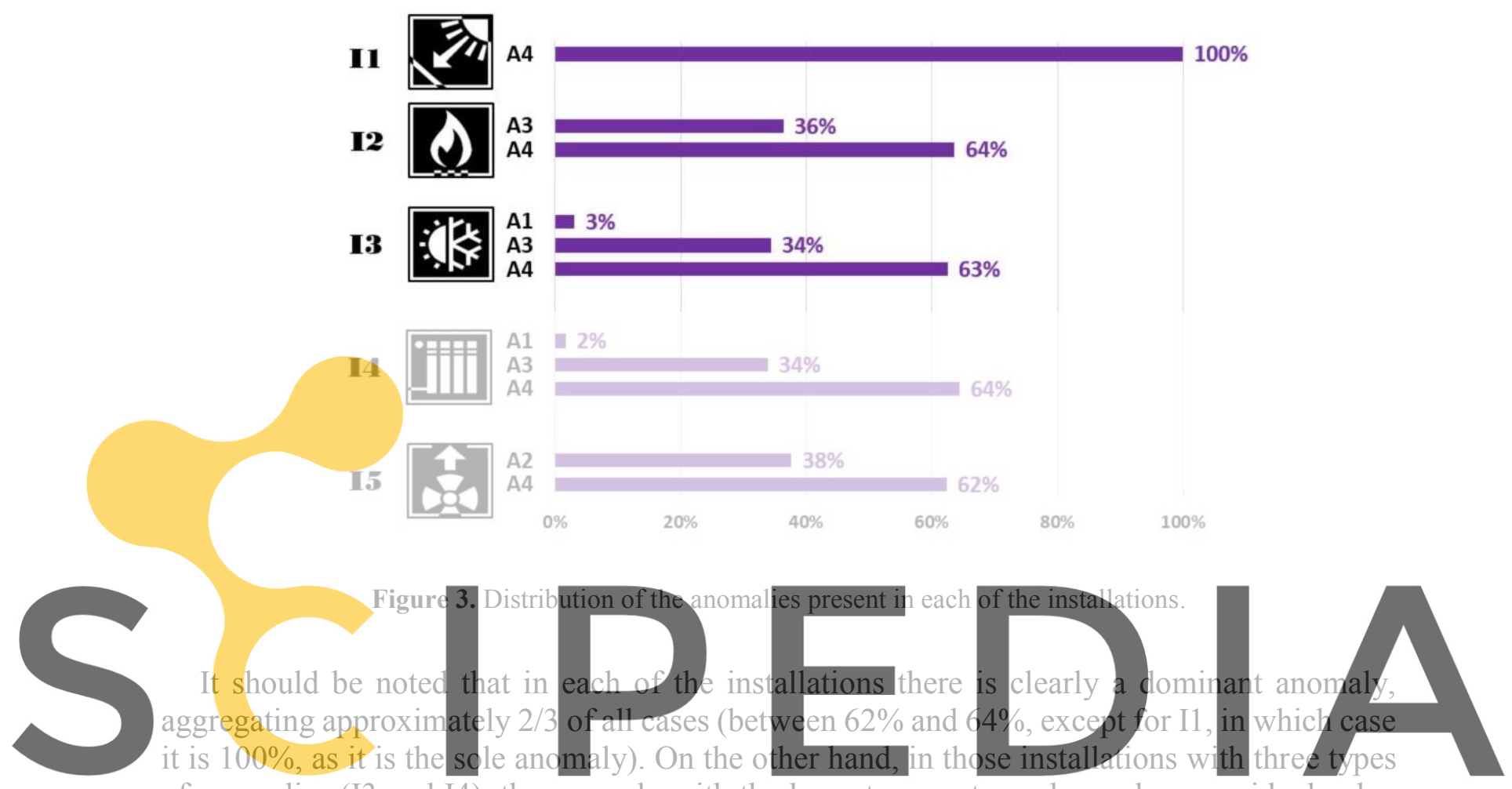

of anomalies (I3 and I4), the anomaly with the lowest percentage always has a residual value

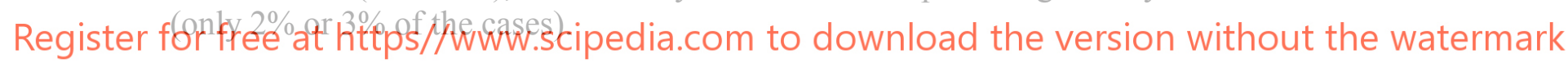

\subsection{Vallues According to the Pathological Origin}

The pathological origin (cause) with the greatest prevalence is OP4, with $35 \%$, followed by OP3 with 34\% (see Figure 4).

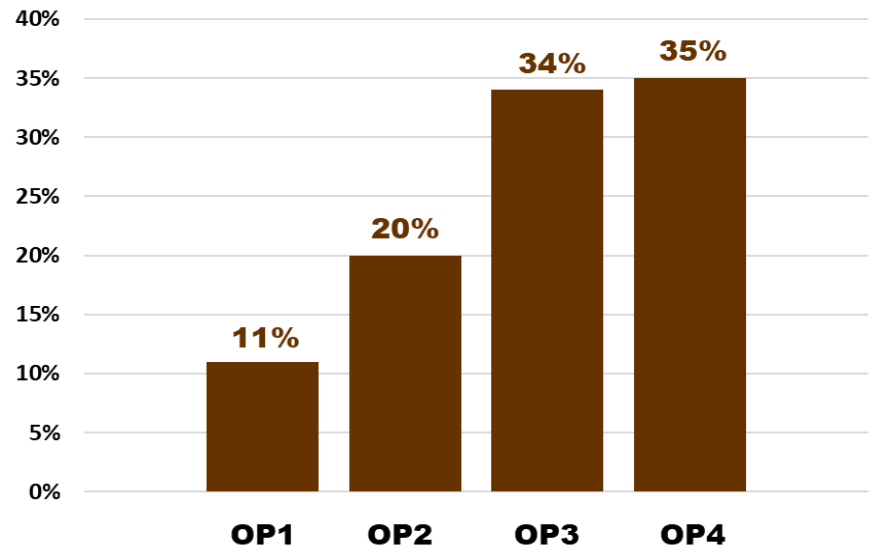

Figure 4. Values from smallest to largest of the different pathological origins found. 
If the origins are broken down for each of the five installations, the following results are obtained:

$$
\begin{aligned}
& \text {-Solar energy }(\mathrm{I} 1)=\mathrm{OP} 3(100 \%) \\
& \text {-Gas (I2) = OP1(45\%) + OP3(36\%)+ OP4(18\%) } \\
& \text {-Cooling (I3) = OP1(16\%) + OP2(13\%) + OP3(31\%)+ OP4(41\%) } \\
& \text {-Heating (I4) = OP1 }(8 \%)+\text { OP2 }(24 \%)+\mathrm{OP} 3(39 \%)+\mathrm{OP} 4(29 \%) \\
& \text {-Ventilation (I5) = OP1(8\%)+ OP2 }(25 \%)+\mathrm{OP} 3(27 \%)+\mathrm{OP} 4(40 \%)
\end{aligned}
$$

It can be seen that the installations I3, I4, and I5 have 4 pathological origins each. In turn, I2 has 3 types of origins, and I1 has only 1 type.

\subsection{Values According to Type of Construction and Type of Anomaly}

One parameter that was also characterised by each of the anomalies was the type of construction in which they occurred. Based on Figure 5, they are most concentrated in 'block dwellings' (V3 $=60 \%$ ), followed by 'attached houses' (V2=26\%). In all cases, the most frequent anomaly were 'dysfunctions' (A4 between 8\% and 39\%), with 'leaks or humidities' (A3 between 3\% and $9 \%$ ) in second place. Lastly, anomaly A1 is not present in the type of construction V2.
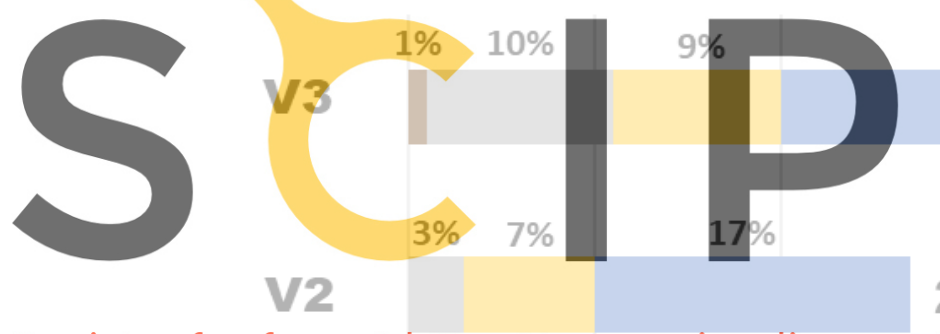

$\square$ A1 $\square$ A2 $\square$ A3 $\square$ A4

Register for free at https//www.scipedia.com to download the version without the watermark

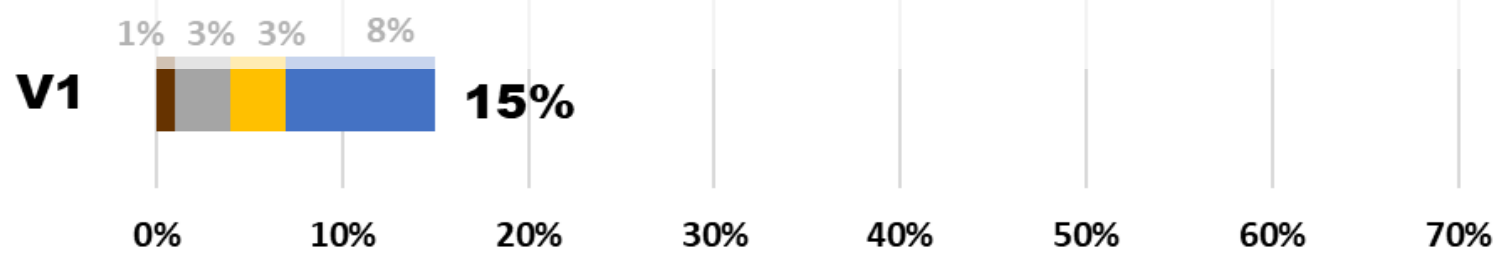

Figure 5. Relation between the type of anomaly and the type of construction.

\subsection{Processes of Functional Deterioration}

A 'process of functional deterioration' (p.f.d.) is the simultaneous and joint interrelation between each installation, its anomalies, and pathological origins; in this regard, each of the cases were studied and their anomalies were counted, differentiating them according to pathological origin.

A total of 30 different p.f.d. were detected in this study (see Table 1), demonstrating the variability of the situations that can take place. The ones with the most cases were I5-OP3-A4 
and I5-OP4-A4 (18 cases each). They are followed by I4-OP2-A4 (14 cases).

With regard to installations, the one with the greatest percentage was I2, with two combinations: I2-OP1-A3 and I2-OP3-A4. Each represented $27 \%$ of anomalies found in gas installations. Solar energy (I1) has only one p.f.d., while cooling (I3) has the greatest variability: 9 p.f.d.

Table 1. Percentages of recurrence of each process of functional deterioration.

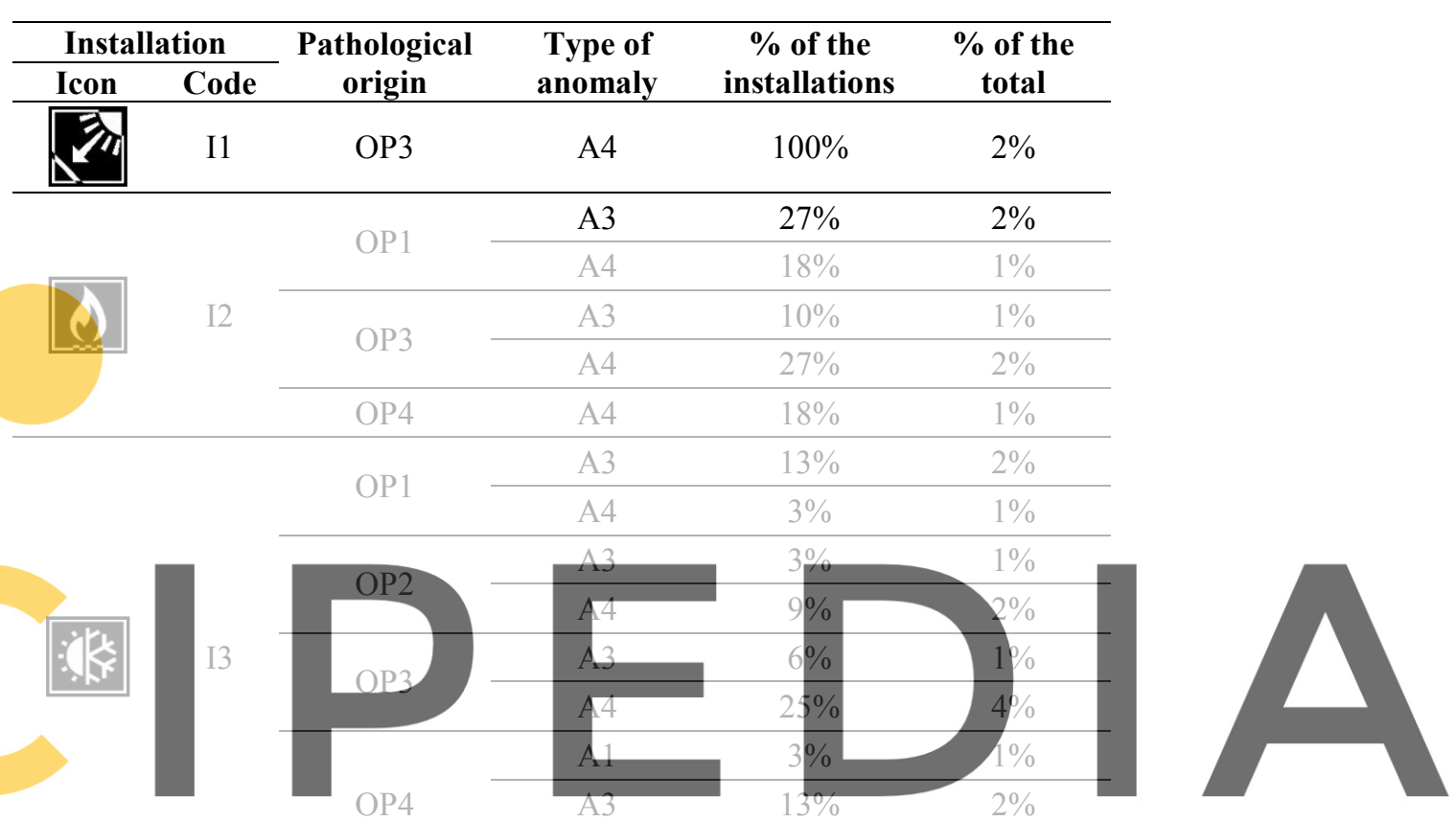

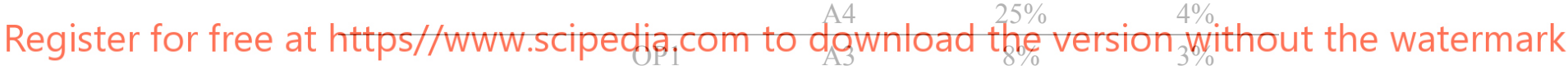

\begin{tabular}{|c|c|c|c|c|}
\hline \multirow{6}{*}{ I4 } & OP2 & A4 & $24 \%$ & $8 \%$ \\
\hline & \multirow{3}{*}{ OP3 } & A1 & $2 \%$ & $1 \%$ \\
\hline & & A3 & $19 \%$ & $5 \%$ \\
\hline & & A4 & $19 \%$ & $5 \%$ \\
\hline & \multirow{2}{*}{ OP4 } & A3 & $6 \%$ & $2 \%$ \\
\hline & & A4 & $22 \%$ & $7 \%$ \\
\hline \multirow{8}{*}{$\mathrm{I} 5$} & \multirow{2}{*}{ OP1 } & A2 & $1 \%$ & $1 \%$ \\
\hline & & A4 & $6 \%$ & $3 \%$ \\
\hline & \multirow{2}{*}{ OP2 } & A2 & $16 \%$ & $6 \%$ \\
\hline & & A4 & $10 \%$ & $4 \%$ \\
\hline & \multirow{2}{*}{ OP3 } & A2 & $4 \%$ & $2 \%$ \\
\hline & & A4 & $23 \%$ & $9 \%$ \\
\hline & \multirow{2}{*}{ OP4 } & A2 & $17 \%$ & $7 \%$ \\
\hline & & A4 & $23 \%$ & $10 \%$ \\
\hline
\end{tabular}


The anomaly A4 ('dysfunctions') is present in all installations, being associated to three types of pathological origin: 'inadequate tail-ends' (OP1), 'irregularities and deficiencies' (OP3), and 'various' (OP4). The combinations occurring lest frequently ( 1 case) are: I2-OP3A3, I3-OP1-A4, I3-OP2-A3, I3-OP4-A1, I4-OP3-A1 and I5-OP1-A4.

The determination and knowledge of each process of functional deterioration have not been identified nor calculated by any of the bibliographic references reviewed for this research. As such, this inclusion is considered to be a novel and important contribution to the technicalscientific knowledge on this type of installations, in addition to assisting technicians in focusing their attention on those combinations that are most problematic. In this manner, it will be possible to reduce anomalies in both the design and construction phases, as well as minimise non-quality costs.

\section{Conclusions}

- It was shown that the installations with the most cases are 'Ventilation' (I5=42\%) and 'Heating' (I4=32\%), representing practically $3 / 4$ of the total. As such, efforts to reduce anomalies should be focused in these installations.

The most frequent pathological origins were 'Diverse' (OP4=35\%) and 'Irregularities and deficiencies' (OP3 $=34 \%)$, and most cases were concentrated in 'block dwellings' $(\mathrm{V} 3=58 \%)$.

Acknowledgements
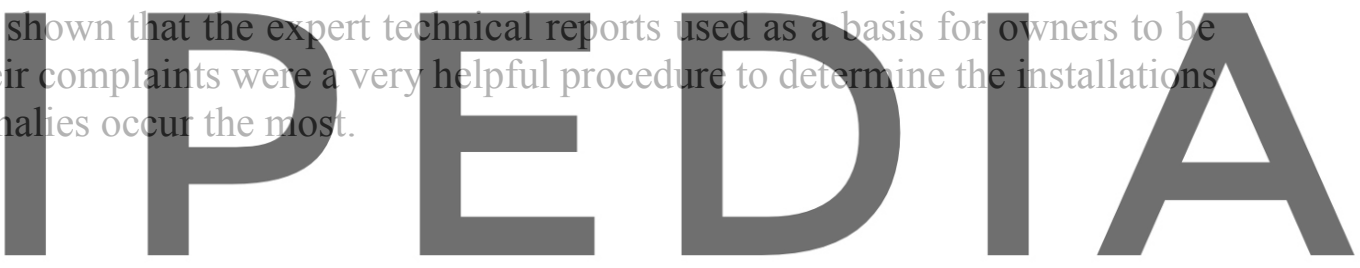

This work was carried out within the Musaat Foundation's Action Plan, in line with the 'Research project on

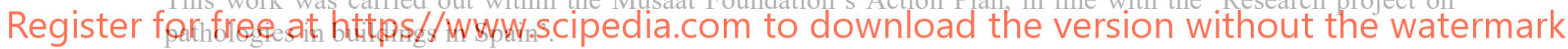

\section{ORCID}

Manuel J. Carretero-Ayuso. https://orcid.org/0000-0002-8082-8996

\section{References}

Behfar, A., Yuill, D. and Yu, Y. (2017). "Automated Fault Detection and Diagnosis Methods for Supermarket Equipment (RP-1615)". Science and Technology for the Built Environment, 23(8), 1253-1266.

Carretero-Ayuso, M. J. and Moreno-Cansado, A. (2016). National Statistical Analysis on Construction Anomalies. MUSAAT Foundation, Madrid.

Cetin, K. S. and Kallus, C. (2016). "Data-Driven Methodology for Energy and Peak Load Reduction of Residential HVAC Systems". Procedia Engineering, 145, 852-859.

Cohen, R., Austin, B., Bannister, P., Bordass, B. and Bunn, R. (2017). "How the Commitment to Disclose in-use Performance can Transform Energy Outcomes for New Buildings". Building Services Engineering Research and Technology, 38(6), 711-727.

Mosaad, S., Issa, U. and Hassan, M. S. (2018). "Risks Affecting the Delivery of HVAC Systems: Identifying and Analysis". Journal of Building Engineering, 16, 20-30. 
MUSAAT (2014-2016). Expert Records and Reports if Accidents, Mútua de Aparejadores y Arquitectos Técnicos, Madrid.

Ruano, A., Silva, S., Duarte, H. and Ferreira, P. M. (2018). "Wireless Sensors and IoT Platform for Intelligent HVAC Control". Applied Sciences, 8(3), 370.

SERJUTECA (2014-2016). Reports and Documents on Accidents Involving Professional Civil Liability of Building Surveyors and Technical Architects, Servicios Jurídicos Técnicos Aseguradores, Madrid.

Turner, W., Staino, A. and Basu, B. (2017). "Residential HVAC Fault Detection using a System Identification Approach". Energy Build., 151, 1-17.

Wu, S. and Sun, J. (2011). "Cross-Level Fault Detection and Diagnosis of Building HVAC Systems". Build. Environ., 46(8), 1558-1566.

Yang, C., Shen, W., Chen, Q. and Gunay, B. (2018). "A Practical Solution for HVAC Prognostics: Failure Mode and Effects Analysis in Building Maintenance". Journal of Building Engineering, 15, 26-32.
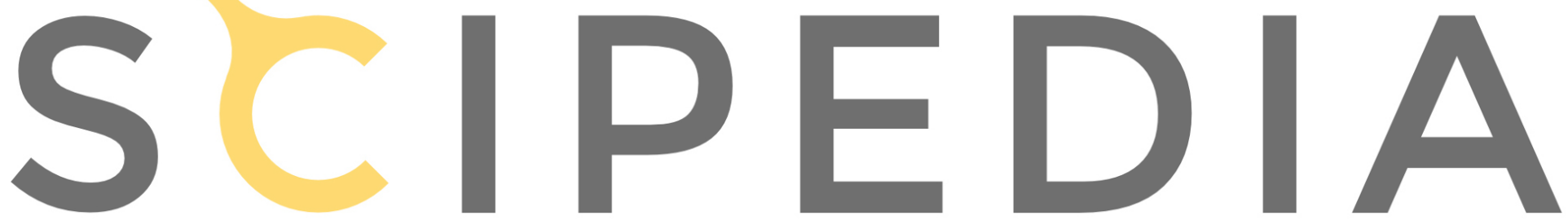

Register for free at https//www.scipedia.com to download the version without the watermark 